\title{
Dependence of Mesomorphism on Molecular Rigidity
}

\author{
R. R. Rola*, G. N. Bhola, U. C. Bhoya \\ Department of Chemistry, Saurashtra University, Rajkot - 360005, Gujarat, India \\ *E-mail address: drucbhoya@gmail.com
}

\begin{abstract}
A novel smectogenic homologous series of twelve homologues synthesized and studied with a view to understand and establish the effect of molecular structure on liquid crystal properties (LC) and LC behaviors of thermotropic homologues. First $\left(\mathrm{C}_{1}\right)$ to last $\left(\mathrm{C}_{16}\right)$ member of a series exhibited only enantiotropically smectogenic property without showing nematic property which is absent even in the monotropic condition. Transition and melting temperature including textures of homologues were determined by an optical polarizing microscopy equipped with a heating stage, texture of a smectic phase are of the type A or C. Smectogenic phase length ranger between $5.1^{\circ} \mathrm{C}$ to $22.6^{\circ} \mathrm{C}$. SmecticIsotropic (Sm-I) thermal stability is $153.55^{\circ} \mathrm{C}$. Analytical, spectral and thermal data supported molecular structures of homologues. LC behaviors of present novel series are compared with the structurally similar homologous series. Transition curves viz. Cr-Sm and Sm-I transition curves of a phase diagram behaved in normal manner.
\end{abstract}

Keywords: Smectic; Enantiotropy; Nematic; Liquid crystals; Mesogenic.

\section{INTRODUCTION}

Liquid crystalline (LC) state [1] either thermotropic or lyotropic are exploited by scientific and technological communities of researchers in the benefit of mankind as a whole, since from is origin. $[2,3,4,5,6]$. Though the research groups working on LC state have different views, aims and objects, but they need novel LC materials in order to continue their research work in the benefit of people. Therefore, our interest in LC study made limited to synthesize novel LC materials through novel homologous series of LC potentials, which may be useful for the thermotropic or lyotropical action purposes. It is possible to vary molecular moieties by changing number of phenyl or other type of rings and central bridge or bridges related to molecular rigidity and lateral or terminal group or groups related to molecular flexibility. Thus, number of homologous series can be synthesized to provide novel LC materials as a source for farther research with different aims, views and object in different disciplines. Thus present study is aimed to synthesize and provide novel LC materials with a view to understand the effect of molecular structure on LC properties and to establish the relation between LC behaviors and molecular structure $[7,8,9,10]$. Number of homologous series has been reported till the date $[11,12,13,14]$. Present investigation consists of a molecule of three phenyl rings bonded through $-\mathrm{COO}$ - and $-\mathrm{CO}-\mathrm{CH}=\mathrm{CH}$ - central bridges with flexible terminal end groups -OR $\left(\mathrm{R}=\mathrm{C}_{\mathrm{n}} \mathrm{H}_{2 \mathrm{n}+1}\right)$ which varies $\mathrm{n}=1,2 \ldots \ldots 16$ and 
unchanging -F, and without any lateral group or groups. Results are to be discussed, compare and interpreted in terms of molecular rigidity and flexibility [15, 16, 17, 18].

\section{EXPERIMENTAL}

\subsection{Synthesis}

n-Alkoxy benzoic acids were prepared from 4-hydroxy benzoic acid, by suitable alkylating agents by modified method of Dave and Vora [19]. $\alpha-4-H y d r o x y$ benzoyl- $\beta-4$ ' fluro phenyl ethylene was prepared by usual established method [20] (M.P.-162 ${ }^{\circ} \mathrm{C}$, Yield$75.2 \%$ ). 4-n-Alkoxy benzoic acids and $\alpha$-4-hydroxy benzoyl- $\beta-4$ ' fluro phenyl ethylene were condensed in 1, 3-dicyclohexylcarbodiimide (DCC), 4-dimethyl aminopyridine (DMAP) and $\mathrm{CH}_{2} \mathrm{Cl}_{2}$ [21] to obtain $\alpha-4-(4$ '-n-Alkoxy benzoyloxy) benzoyl- $\beta-4$ " fluro phenyl ethylenes. Final products were individually decomposed, filtered, washed, dried and purified till the constant transition temperatures obtained.

The synthetic route to the novel homologous series of ethylene derivatives is under mentioned in scheme-1.

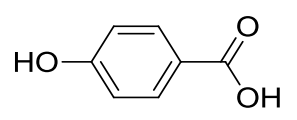<smiles>CC(=O)c1ccc(O)cc1</smiles><smiles>COC(=O)C(C)(Br)Br</smiles><smiles>COC(=O)C(C)C(=O)OC</smiles>

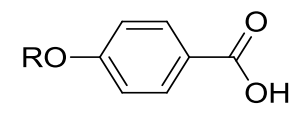

[A]<smiles>O=C(/C=C/c1ccc(F)cc1)c1ccc(O)cc1</smiles>

[B]<smiles></smiles>

Scheme 1. Synthetic route to the novel series. 


\subsection{Characterization}

Some of members of a novel series as the representative member of a series were characterized by elemental analysis (Table-1), Infrared spectroscopy, ${ }^{1} \mathrm{H}$ NMR spectra and mass spectroscopy. Microanalysis was performed on EuroEA Elemental Analyzer. IR spectra were recorded on Shimadzu FTIR Model-IRAffinity-1S (MIRacle 10), ${ }^{1} \mathrm{HNMR}$ spectra were recorded on Bruker spectrometer using $\mathrm{CDCl}_{3}$ as a solvent and mass spectra were recorded on Shimadzu GC-MS Model No.QP-2010.

\subsection{Analytical data}

Table 1. Elemental analysis for (1) Ethyloxy (2) Pentyloxy (3) Octyloxy derivatives.

\begin{tabular}{|c|c|c|c|c|c|c|c|}
\hline \multirow{2}{*}{ Sr. No. } & \multirow{2}{*}{$\begin{array}{l}\text { Molecular } \\
\text { formula }\end{array}$} & \multicolumn{3}{|c|}{ Elements $\%$ Found } & \multicolumn{3}{|c|}{ Elements \%Calculated } \\
\hline & & $\mathrm{C}$ & $\mathrm{H}$ & $\mathrm{O}$ & $\mathrm{C}$ & $\mathrm{H}$ & $\mathrm{O}$ \\
\hline 1 & $\mathrm{C}_{24} \mathrm{H}_{19} \mathrm{FO}_{4}$ & 73.86 & 4.90 & 16.36 & 73.84 & 4.91 & 16.39 \\
\hline 2 & $\mathrm{C}_{27} \mathrm{H}_{25} \mathrm{FO}_{4}$ & 75.08 & 5.80 & 14.77 & 74.98 & 5.83 & 14.80 \\
\hline 3 & $\mathrm{C}_{30} \mathrm{H}_{31} \mathrm{FO}_{4}$ & 75.98 & 6.58 & 13.44 & 75.93 & 6.58 & 13.49 \\
\hline
\end{tabular}

\section{Spectral Data}

\section{${ }^{1}$ HNMR in ppm for Methyloxy Derivative}

8.1039-8.0817 (d 2H Ar-H ), 8.0393-8.0177 (d 2H Ar-H), 7.7423-7.7031 (d 1H H-C=C j Hz), 7.5917-7.5566 (d 2H Ar-H), 7.4101-7.3709 (d 1H H-C=C j Hz), 7.2998-7.2781 (d 2H Ar-H), 7.0661-7.0232 (d 2H Ar-H), 6.9380-6.9158 (d 2H Ar-H), 3.8316 (s 3H - $\mathrm{OCH}_{3}$ ). The NMR data are reliable with the molecular structure.

\section{${ }^{1}$ HNMR in ppm for Heptyloxy Derivative}

8.0865-8.0644 (d 2H Ar-H), 8.0380-8.0163 (d 2H Ar-H), 7.7424-7.7032 (d 1H H-C=C j $\mathrm{Hz}$ ), 7.5920-7.5528 (d 2H Ar-H), 7.4103-7.3112 (d 1H H-C=C j Hz), 7.2983-7.2766 (d 2H Ar-H), 7.0663-7.0234 (d 2H Ar-H), 6.9204-6.8821 (d 2H Ar-H), 3.9907-3.9579 (t 2H O$\left.\mathrm{CH}_{2}-\right), 1.7873-1.7171\left(\mathrm{p} 2 \mathrm{H} \mathrm{O}-\mathrm{CH}_{2}-\mathrm{CH}_{2}\right), 1.4385-1.2421\left(\mathrm{p} 8 \mathrm{H}-\mathrm{CH}_{2}-\mathrm{CH}_{2}-\right), 0.8459-0.8119$ (t $-\mathrm{CH}_{3}$ ). The NMR data are reliable with the molecular structure.

\section{IR in $\mathbf{~ m}^{-1}$ for Propyloxy Derivative}

3066.92 (w, C-H str. of Aromatic ring), 2970.48, 2881.75 (s C-H str. of alkane, sp3 Carbon), 2357.09, 2332.02 (combination of C-H str.), 1728.28 (s $\mathrm{C}=\mathrm{O}$ str. ester), 1658.84, 1599.04, 1508.38 ( $\mathrm{C}=\mathrm{C}$ str. In Aromatic ring), 1417.73 (m C-H bend. Alkane) 1276.92 ( $\mathrm{s}$ Aromatic C-O str. and $\mathrm{C}=\mathrm{C}$ str.), 1170.83, 1074.39, 1016.52, (s Aliphatic C-O str. and so and overtone C-H str.), 829.42, 758.05, 684.75 (m-o-p sub. phenyl ring). The IR data are consistent with the molecular structure.

IR in $\mathbf{~ m}^{-1}$ for Tetradecyloxy Derivative

3066.92(w, C-H str. of Aromatic ring), 2920.32, 2848.96 (s C-H str. of alkane, sp3 Carbon), 2357.09, 2332.02 (combination of $\mathrm{C}-\mathrm{H}$ str.), 1726.35 (s $\mathrm{C}=\mathrm{O}$ str. ester), 1656.91, 1597.11, 1510.31 ( $\mathrm{C}=\mathrm{C}$ str. in Aromatic ring), 1413.87 (m C-H bend. Alkane) 1263.42 (s Aromatic C-O str. and C=C str.), 1166.97, 1072.46, 1028.09, 985.66, (s Aliphatic C-O str. and 
so and overtone C-H str.), 821.70, 640.29, 601.81 (m-o-p sub. phenyl ring). The IR data are consistent with the molecular structure.

Mass spectra of Butyloxy Derivative

$\mathrm{m} / \mathrm{z}$ (rel.int\%): 418(M)+, 241, 177,165, 121, 101, 93, 76, 65, 44

Mass spectra of Hexyloxy Derivative

$\mathrm{m} / \mathrm{z}$ (rel.int\%): 446(M) +, 241, 205, 162, 121, 101, 93, 76, 65, 44

\section{RESULTS AND DISCUSSION}

$\alpha$-4-Hydroxy benzoyl $\beta$-4' fluro phenyl ethylene is a non-liquid crystal component of the homologues. However smectic type mesomorphism is indeed on linking it with 4-nalkoxy benzoic acids by steglich esterification. Dimerization of n-alkoxy benzoic acid disappears on esterification. Transition temperatures (Table-2) as determined from an optical polarizing microscopy were plotted versus the number of carbon atoms present in n-alkyl chain of left n-alkoxy terminally situated and group (Figure-1). Transition curves Cr-Sm and Sm-I are drown smoothly linking like or related points as shown in a phase diagram showing phase behaviors of a series. Cr-Sm transition curve follows partly zigzag path of rising and falling in usual established manner with overall descending manner as series is ascended. SmI transition curve behaved normal manner with exhibition of odd even effect. Sm-I transitions curves for odd and even numbers merges into each other at the butyloxy $\left(\mathrm{C}_{4}\right)$ homologue of a series and then it prolong as a single curve till $\mathrm{C}_{16}$ homologue. Thermal stability for smectic is $153.55{ }^{\circ} \mathrm{C}$ and the mesophase length ranges from $5.1{ }^{\circ} \mathrm{C}\left(\mathrm{C}_{12}\right)$ to $22.6{ }^{\circ} \mathrm{C}$ at the $\mathrm{C}_{16}$ member of a series. Smectogenic mesophase formation commences from very first member $\left(\mathrm{C}_{1}\right)$ to the lost $\left(\mathrm{C}_{16}\right)$ member of a series in enantiotropic manner without exhibition of nematic property. Thus, present novel series is fully smectogenic with middle ordered melting type.

Table 2. Transition temperatures in ${ }^{\circ} \mathrm{C}$.

\begin{tabular}{|c|c|c|c|c|}
\hline \multirow{2}{*}{$\begin{array}{c}\text { Compound } \\
\text { No. }\end{array}$} & $\begin{array}{c}\mathbf{R}=\mathbf{n}-\text { alkyl chain } \\
\mathbf{C}_{\mathbf{n}} \mathbf{H}_{\mathbf{2 n + 1}}\end{array}$ & \multicolumn{3}{|c|}{ Transition temperatures in ${ }^{\mathbf{0}} \mathbf{C}$} \\
\cline { 3 - 5 } & 1 & 177.8 & $\mathbf{N}$ & Isotropic \\
\hline 1 & 2 & 167.7 & - & 189.0 \\
\hline 2 & 3 & 148.8 & - & 173.5 \\
\hline 3 & 4 & 147.2 & - & 160.2 \\
\hline 4 & 5 & 145.1 & - & 154.8 \\
\hline 5 & 6 & 142.8 & - & 152.4 \\
\hline 6 & 7 & 139.3 & - & 149.0 \\
\hline 7 & 8 & 137.6 & - & 145.0 \\
\hline 8 & 10 & 135.1 & - & 149.5 \\
\hline 9 & 12 & 143.8 & - & 143.1 \\
\hline 10 & 14 & 122.7 & - & 148.9 \\
\hline 11 & 16 & 117.4 & - & 137.2 \\
\hline 12 & & & & 140.0 \\
\hline
\end{tabular}

Sm, Smectic; N, Nematic 


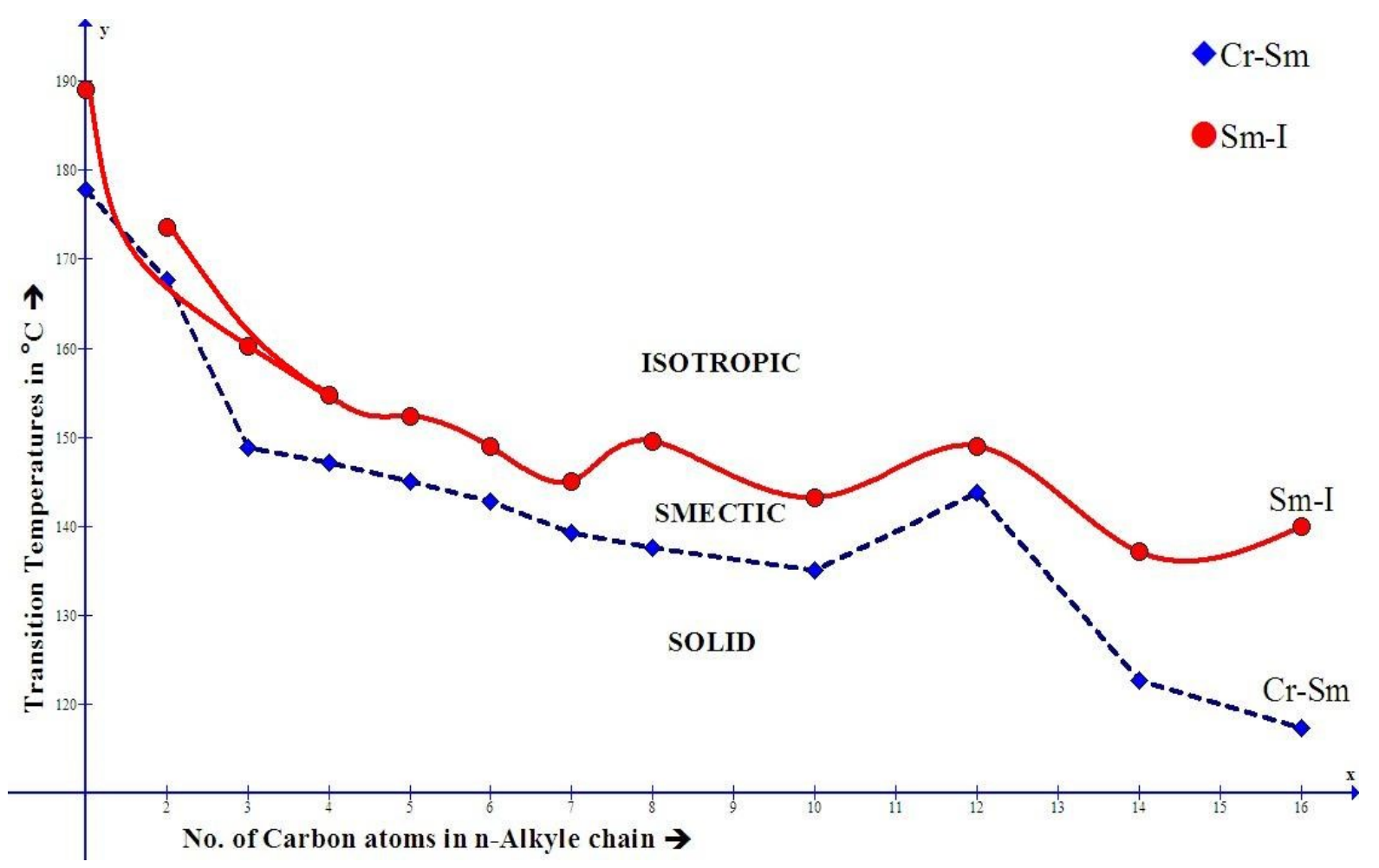

Figure 1. Phase Behavior of Series.

Linking of dimeric n-alkoxy benzoic acid by steglich esterification with $\alpha$-4-hydroxy benzoyl $\beta$-4'-fluro phenyl ethylene increased molecular length, polarity and polarizibility, rigidity and flexibility and suitable magnitudes of anisotropic forces of intermolecular lateral and end to end attractions to such an extent that, lamellar packing of molecules occur in solid crystalline state. Thus, molecules of each homologue $\left(\mathrm{C}_{1}\right.$ to $\left.\mathrm{C}_{16}\right)$ disaligned of angle ninety degree to from focal conic networking as layers. Such layers are slides over one another under the influence of exposed thermal vibrations with different magnitudes of resistivity depending upon enthalpy $(\Delta \mathrm{H})$ value acquired during formation, which maintains thermal stabilization and resistivity towards exposed heat and caused to appear smectic mesophase formation throughout the series. However, the residual forces of end to end attractions is insufficient for all the homologues to maintain statically parallel orientational order of molecules in floating condition on the surface to exhibit nematic phase, but directly converted to isotropic state in which the molecules of homologues $\left(\mathrm{C}_{1}\right.$ to $\left.\mathrm{C}_{16}\right)$ randomly oriented in all possible directions with high order of disorder or high entropy $(\Delta S=\Delta H / T)$. Isotropic melt on cooling reacquire smectic phase by passing monotropic nematic mesophase formations. Thus, only smectogenic mesomorphic phase is exhibition enantiotropic manner directly and transform in to crystalline state without exhibition of monotropic nematic mesophase formation. Disappearance of dimerization of n-alkoxy benzoic acid is attributed to the breaking of hydrogen bonding between two molecules by esterification process. Disappearance of odd-even effect from and beyond $\mathrm{C}_{4}$ homologues in Sm-I transition curve is attributed to the coiling or flexing or bending or coupling of longer n-alkyl chain $\left(\mathrm{C}_{5}\right.$ to $\left.\mathrm{C}_{16}\right)$ with major axis of the core structure of the molecules. Average thermal stability indicates transition and melting temperatures above $100{ }^{\circ} \mathrm{C}$. However, smectogenic mesophase stabilize after between $5.1{ }^{\circ} \mathrm{C}$ and $22.6{ }^{\circ} \mathrm{C}$. Thus, thermal stability facilitated for majority of homologues is low which is operated by 
paramagnet dipolemoment across the long molecular axis, dipole-dipole interactions, electronic interactions, dispersion forces etc. conducive to mesophase formation. Thus, series under discussion is fully smectogenic with absence of nematogenic character. Some mesomorphic properties of presently investigated novel homologues series-1 are compared with structurally similar known homologous series- X [22] and Y [23] as under in figure -2.

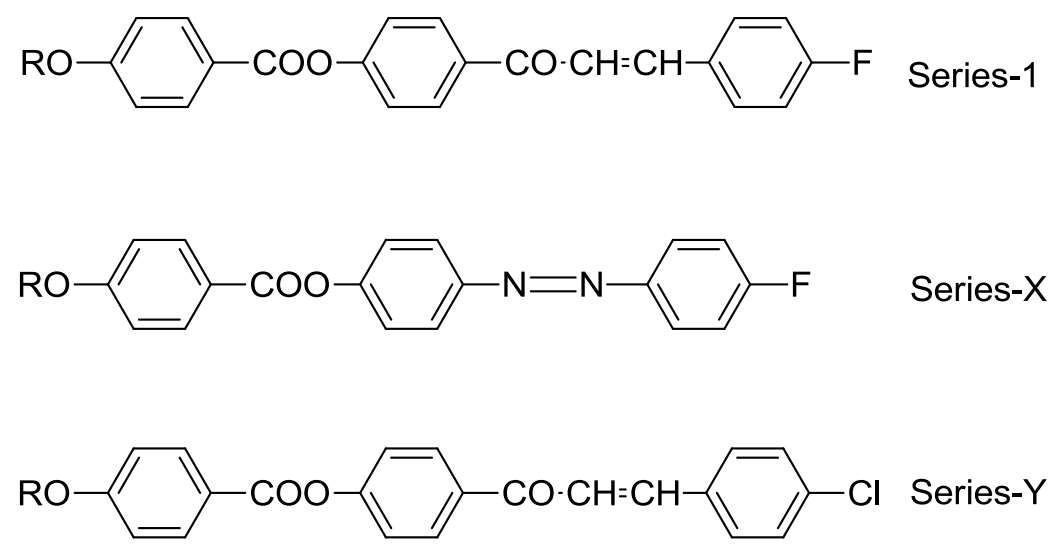

Figure 2. Structurally similar series.

Homologous series-1 and series-X and $\mathrm{Y}$ selected for comparative study are identical with respect to three phenyl rings, a central bridge -COO- linking first and middle phenyl ring and the left n-alkoxy terminal end group for the same homologues. However, they differ with respect to either central bridges (series 1 and $\mathrm{X}$ ) or terminally situated tail group (series-1 and $\mathrm{Y}$ ). Homologous series 1 and $\mathrm{X}$ differ by central bridges $-\mathrm{CO}-\mathrm{CH}=\mathrm{CH}$ - and $-\mathrm{N}=\mathrm{N}$ - keeping tail group $-\mathrm{F}$ intact whereas series 1 and $\mathrm{Y}$ differ by a tail group $-\mathrm{F}$ and $-\mathrm{Cl}$ respectively, keeping central bridge $-\mathrm{CO}-\mathrm{CH}=\mathrm{CH}$ - unchanged. Therefore, molecular rigidity differs for series 1 and $\mathrm{X}$ but molecular flexibility for the same homologues remains unaltered; where as molecular flexibility alters for the series $1 \& \mathrm{Y}$, but molecular rigidity remains unaltered. However, suitable or unsuitable magnitudes of anisotropic forces of intermolecular attraction to stabilize or destabilize liquid crystalline state depend upon the combine effect of molecular rigidity and flexibility. The combined effect of molecular rigidity and flexibility varies from homologues to homologue in the same series or for the same homologue from series to series. Thus, variation in mesomorphic behaviors and the degree of mesomorphism depend upon the charging part of molecules, operating molecular rigidity or flexibility responsible for suitable magnitudes of anisotropic forces of intermolecular end to end and /or lateral attractions.

Following table-3 represents some LC properties or Series 1, X and Y in comparative manner.

Table 3. Average thermal stabilities in ${ }^{\circ} \mathrm{C}$.

\begin{tabular}{cccc}
\hline Series $\rightarrow$ & 1 & $\mathrm{X}$ & $\mathrm{Y}$ \\
\hline $\begin{array}{c}\text { Smectic-Isotropic or } \\
\text { Smectic-Nematic }\end{array}$ & 153.55 & 116.80 & - \\
& $\left(\mathrm{C}_{1}-\mathrm{C}_{16}\right)$ & $\left(\mathrm{C}_{8}-\mathrm{C}_{16}\right)$ & \\
Commencement of & $\mathrm{C}_{1}$ & $\mathrm{C}_{8}$ & - \\
Smectic mesophase & & & \\
\hline
\end{tabular}




\begin{tabular}{|c|c|c|c|}
\hline Nematic-Isotropic & - & $\begin{array}{c}189.70 \\
\left(\mathrm{C}_{1}-\mathrm{C}_{10}\right)\end{array}$ & $\begin{array}{c}149.4 \\
\left(\mathrm{C}_{5}-\mathrm{C}_{14}\right)\end{array}$ \\
\hline $\begin{array}{l}\text { Commencement of } \\
\text { nematic phase }\end{array}$ & - & $\mathrm{C}_{1}$ & $\mathrm{C}_{5}$ \\
\hline $\begin{array}{l}\text { Total Mesophase length } \\
\text { range }(\mathrm{Sm}+\mathrm{N})\end{array}$ & $\begin{array}{l}5.1\left(\mathrm{C}_{12}\right) \\
\text { to } 22.6\left(\mathrm{C}_{16}\right)\end{array}$ & $\begin{array}{l}15.0\left(\mathrm{C}_{16}\right) \\
\text { to } 103.0\left(\mathrm{C}_{6}\right)\end{array}$ & $\begin{array}{c}14.0\left(\mathrm{C}_{8}\right) \\
\text { to } 25.0\left(\mathrm{C}_{12}\right)\end{array}$ \\
\hline
\end{tabular}

On comparing the mesomorphic behaviors of homologous series-1 of present investigation and the series- $\mathrm{X}$ and $\mathrm{Y}$ chosen for comparison;

oSeries-1 is only smectogenic, series- $\mathrm{X}$ is smectogenic in addition to nematogenic and a series-Y is only nematogenic.

o Smectic thermal stability of series- 1 is higher than a series- $\mathrm{X}$ and $\mathrm{Y}$.

oNematic thermal stability of series- $X$ is greater than the series- $Y$ and 1.

$\circ$ Smectic mesophase commences earlier for the series-1 $\left(C_{1}\right)$ and later from $C_{8}$ of the series- $\mathrm{X}$, whereas it does not commence till the last member of a series- $\mathrm{Y}$.

oNematic mesophase commences from $C_{1}$ and $C_{5}$ homologues for the series- $X$ and $Y$ respectively, but it does not commence till the last member of a series- 1 .

oTotal mesophase length range $(\mathrm{Sm}+\mathrm{N})$ is the highest for series- $\mathrm{X}$ and then for series-1 and then lowest of series-Y.

The absence of nematic property in resent novel series is attributed to the relative rigidity offered by a central groups $-\mathrm{CO}-\mathrm{CH}=\mathrm{CH}-$ and $-\mathrm{N}=\mathrm{N}$ - which links the phenyl rings through at least one multiple bond. But, $-\mathrm{CO}-\mathrm{CH}=\mathrm{CH}$ - is longer than $-\mathrm{N}=\mathrm{N}$ - which increases molecular polarity, polarizibility and the permanent dipole moment across the long molecular axis. The stereochemistry of the units through preserve the linearity of the molecule, but usually result in more and less thermally stable mesophase for the homologues of series-1 and $\mathrm{X}$ respectively. From this comparison, it is clear that, due to increased length of uncommon central bridges and common tail group $-\mathrm{F}$, the homologues of series- 1 resist the forces of thermal break down well enough to yield smectic phase from very first member of a series-1 and from octyloxy member $\left(\mathrm{C}_{8}\right)$ of a series-X. Thus, all the homologues of series- 1 and the higher homologues of series- $\mathrm{X}$ (from and beyond $\mathrm{C}_{8}$ ) do get exhibited smectic mesophase formation earlier (series-1) and later (series-X) relatively at higher and lower temperatures respectively; resulting into high and low thermal stability for smectic. Thus, lamellar packing of molecules facilitated smectic mesophase formation as a consequence of molecular rigidity difference between series-1 and X. Thus, display of only smectic property in absence of nematic property in case of series- 1 indicates that, the forces holding the plane of the layers together in the rigid crystal are weaken relatively to the attraction between the molecules within a given layer at solid-mesomorphic transition temperature and the layers may become free to slide and rotate over one another giving smectic phase for series-1 and X. However on heating the smectic phase to a higher temperature, the intermolecular end to end forces between the sides of the molecules weaken to such an extent for the homologues of series-1 and $\mathrm{X}$, that resultant intermolecular cohesive forces do not permit the molecules to slide out of the layers and statistically parallel orientation are not permitted for all homologues of series-1 $\left(\mathrm{C}_{1}\right.$ to $\left.\mathrm{C}_{16}\right)$ but permitted for maintenance of nematic phase of homologues $\mathrm{C}_{8}, \mathrm{C}_{10}$ of 
series- $\mathrm{X}$ and its lower homologues $\mathrm{C}_{1}$ to $\mathrm{C}_{6}$ in absence of smectic phase, because, $\mathrm{C}_{12}, \mathrm{C}_{14}$ and $\mathrm{C}_{16}$ are only smectogenic. Thus, only smectic property exhibited by series- 1 and partly only nematic $\left(\mathrm{C}_{1}\right.$ to $\left.\mathrm{C}_{6}\right)$, partly only smectic $\left(\mathrm{C}_{12}, \mathrm{C}_{14}, \mathrm{C}_{16}\right)$ and partly smectic plus nematic $\left(\mathrm{C}_{8}\right.$, $\mathrm{C}_{10}$ ) which exhibited by series-X. Absence of lamellar packing of molecules in the crystal lattice of series-Y, in which $-\mathrm{F}$ is replaced by $-\mathrm{Cl}$ as flexible tail group, the changing molecular flexibility, and keeping rigidity same as series-1 permit only statistically parallel orientational order of molecules $\left(\mathrm{C}_{5}-\mathrm{C}_{14}\right)$ and hinders lamellar packing of molecules thought the series-Y. Therefore size of tail group $(-\mathrm{Cl}>-\mathrm{F})$ play an important role in mesomorphic behaviors of structurally dissimilar unit of a molecules. Early commencement of the smectic phase in comparison of series- 1 and $\mathrm{X}$ is related with less noncoplanarity of the molecules. Inequality of the extent of noncoplanarity results into smectogenic mesophase formation and lamellar packing of molecules early or late, depending upon changing unit of comparing molecular structures. Total mesophase length range variations depend upon the resistivity of exposed thermal vibrations from series to series for the same homologue as a consequence of changing molecular rigidity and flexibility which are thermodynamically related with enthalpy change of transition mesomorphic to mesomorphic or Cr-M or M-I $(\Delta H)$ of individual homologue of the same series and for the same homologue from series to series. Thus, highest thermal resistivity of series- $X$ and the lowest thermal resistivity of series- $Y$ as well as intermittent thermal resistivity of present series under comparative study follow thermo dynamical concept.

\section{CONCLUSIONS}

oA novel homologous series consisted of three phenyl rings and two central bridges $\mathrm{COO}-$ and $-\mathrm{CO}-\mathrm{CH}=\mathrm{CH}$ - with para substituted $-\mathrm{OR}$ and $-\mathrm{F}$ tail groups is fully smectogenic without exhibition of nematic property.

o Replacement of a central group $-\mathrm{CO}-\mathrm{CH}=\mathrm{CH}-$ by $-\mathrm{N}=\mathrm{N}$ - can induce partly smectic and predominantly nematic property.

oReplacement of tail group $-\mathrm{F}$ by $-\mathrm{Cl}$ induces only nematic property or eliminates smectic property. Thus, size of tail group of same group of periodic table affects mesomorphic characteristics.

oLiquid crystal properties are very sensitive and susceptible to molecular structure.

oPresent investigation is useful in the study of binary system and pharmaceutical treatment as well as agricultural growth.

oLC properties and the degree of mesomorphism are the function of molecular structure as a consequence of molecular rigidity and flexibility.

\section{Acknowledgement}

Authors acknowledge thanks to the Department of Chemistry (DST-FIST Funded \& UGC-SAP Sponsored), Saurashtra University, Rajkot, for research work. Authors are also thankful to Dr. A.V. Doshi, Ex. Principal M.V.M. Science and Home Science College Rajkot, for his valuable co-operation during present investigation as and when needed. Also thanks to the National Facility for Drug Discovery through New Chemical Entities (NCE's) for analysis of samples. 


\section{References}

[1] Reinitzer, F., Monatsh (1888). 9, 421.

[2] Naemura, S. (2001). Advance LCD technologies, Displays, 22 (1), 1.

[3] Talwa, I., Dr.Salnana Shahi, Ramteke,V. \& Syed, I. (2012). "Liquid crystal Pharmaceutical Application: A Review", "IJPRAS" International journal of Pharmaceutical Research and Allied Science, 1(2), 06-11.

[4] Hertz, E., Laorel, B., \&Faucher,O. (2011). Nature photon, 5, 78-79.

[5] Calliste, C.A., Bail, J.C., Trouilas, P., Pouget, C., Chulia.A.J. \& Duroux, L.J. (2001). Anticancer Res., 21, 3949-3956.

[6] Gray, G. W., \& Windsor, P. A. (1974). Liq.Cryst. and Plastic Cryst., The role of liquid crystals in life processes by Stewart G.T., 1, 308-326.

[7] Gray, G. W. (1962). Molecular Structure and the Properties of Liquid Crystal. Academic Press: London.

[8] Gray, G. W., \& Windsor, P.A. (1974). Liq. Cryst. Plastic Cryst., Ellis Horwood: Chichester, U.K., 1 (4), 103-153.

[9] Gray, G.W. \& Jones, B. (1954).Mesomorphism and Chemical Constitution part-III.4alkoxy benzoic acid, J. of Chem. Soc., pp.2556-2562.

[10] Imrie, C.T. (1999). Liquid crystal dimers, Structure, Bond, 95,149-192.

[11] Demls, D. (1988). 100 years of Liquid Crystal Chemistry, Mol. Cryst. Liq. Cry., 165, pp. $45-84$.

[12] Demus, D. (1989). Plenary lectures 100 years of Liquid Crystal Chemistry, Thermotropic liquid crystals with conventional and unconventional molecular structure, Liq. Cry., 5, pp. 75-110.

[13] Imrie, C.T. \& Luckhrust, G.R. (1998). Liquid Crystal dimers and oligomers: Handbook of liquid crystal, law molecular liquid crystals, 2B, Demus,D., Goodly, J.W., Spiess, H.W. and Vill,V.,willey-VCH, weinhei, 801-833.

[14] Vora, R.A., Prajapati, A.K., Kevat, J.B. \& Raina, K.K. (2001).Mesogenic properties and the effect of 1,2,4 trisubstitution on the central benzene nucleus of a three ring mesogens. Liq.cryst.28, 983-989.

[15] Hird, M., Toyne, K. J., Gray, G. W., Day, S. E., \& Mc Donnell, D. G. (1993). Liq. Cryst., 15, 123.

[16] Collings, P.J. \& Hird, M., (1998). Introduction to liquid crystals chemistry and physics, Taylor and Francis, U.K.

[17] Marcos, M., Omenat, A., Serrano, J. L., \& Ezcurra, A. (1992). Adv. Mater., 4, 285.

[18] Hird, M., Toyne, K. J., \& Gray, G. W. (1993). Liq. Cryst., 14, 741.

[19] Dave, J. S., \& Vora, R. A., (1970). Liquid Crystal and Ordered Fluids, Plenum Press: New York, Graw, G. W. (1958). Steric effect in conjugated systems. Ed., Butterworths, London, 477.

[20] Patel, R. B., Patel, V. R., \& Doshi, A. V. (2012). Mol. Cryst. Liq. Cryst., 552, 3-9. 
[21] Nagaveni, N.G., \& Prasad, V., (2013). “Azo substituted V-shaped liquid crystalline compounds: synthesis and mesophase characterization", Phase Tran. 86, 12, 1227 1240.

[22] Dave, J.S., Upasani, C.B., \& Patel, P.D. (2010). Mol.Cryst.Liq.Cryst., 73, 533.

[23] Chauhan, H.N., \& Doshi., A.V. (2013). Mol.Cryst.Liq.Cryst., 575(1), 96-103. 